\title{
LA RAZONABILIDAD EN LA ESCENA JUDICIAL: HACIA UN "HÉRCULES" TERRENAL
}

\author{
REASONABILITY IN THE COURT SCENE: TOWARDS AN \\ EARTHLY HERCULES
}

FRANCO GATTI*

\section{Resumen}

El presente trabajo tiene por objeto discutir las implicancias que adquiere la noción de razonabilidad en el derecho, deteniéndose especialmente en los modos en que impacta en la configuración de un modelo de sujeto de derecho. A partir de este análisis, y considerando el carácter "poroso" del concepto estudiado, se abordará el rol que desempeña la judicatura para atribuirle una significación.

Específicamente, la investigación profundizará en las diversas formas en que los tribunales han utilizado la categoría de la "razonabilidad" para responder a circunstancias imprevistas por la legislación y que reeditan el histórico debate entre la preservación de la estabilidad jurídica y la necesaria flexibilidad de las decisiones judiciales.

\section{Palabras Clave}

Razonabilidad, racionalidad, jurisdicción, flexibilidad, estabilidad.

Artículo recibido para su evaluación el 18 de agosto 2020, y aprobado para su publicación el 20 de diciembre de 2020

* Candidato a Doctor en Derecho y a Magíster en Derecho Público, por la Universidad Nacional de Rosario. Email: francogatti517@hotmail.com. 


\begin{abstract}
This work discusses the impact of reasonability in law, focusing in the ways that it influences the configuration of a model of a subject of law. From this analysis, and considering its variable nature, we will go through the role that the judges plays in assigning it a meaning.

In particular, we will put our attention on the different ways that courts have used the reasonability category to answer to circumstances unexpected by the legislation and that change the historical debate between the preservation of juridical stability and the necessary flexibility of court decision.
\end{abstract}

\title{
Key Words
}

Reasonability, rationality, jurisdiction, flexibility, stability.

\section{RACIONALIDAD Y RAZONABILIDAD EN EL SUJETO DE DERECHO.}

\section{Elementos conceptuales.}

A partir del Renacimiento y del traslado de la centralidad hacia la razón humana, "el hombre se convierte en el primer y auténtico subjectum, sobre el que se fundamenta todo ente en lo tocante a su modo de ser y su verdad". Esta circunstancia tiene sus efectos específicos en el universo jurídico, donde el sujeto de derecho es configurado a partir de un modelo de racionalidad y con el él se diseña, simultáneamente, un patrón de conducta.

Inicialmente, debe decirse que existen múltiples desarrollos relativos a la posibilidad de trazar distinciones entre la racionalidad y la razonabilidad. Sibley indica que un hombre es racional cuando no sabemos a qué fines apuntará en su conducta, solo sabemos que, sean cuales sean, utilizará la inteligencia para perseguirlos; mientras que aquél dispuesto a actuar razonablemente, en lo que respecta a otros, estará dispuesto a gobernar su conducta por un principio de equidad, a partir del cual él y ellos pueden razonar en común, y también que él admitirá datos sobre las consecuencias de sus acciones propuestas sobre su bienestar, en sí mismo, relevantes para

1 HEIDEGGER, Martin: "La época de la imagen del mundo". En: Caminos de Bosque, Alianza, MADRID, 1996. p. 104. 
sus decisiones. Esta disposición no se deriva ni se opone a la disposición de ser racional. Sin embargo, es incompatible con el egoísmo, porque está esencialmente relacionado con la disposición a actuar moralmente ${ }^{2}$.

Silvia Zorzetto, por su parte, afirma que, si bien lo racional está vinculado con un agente ideal perfectamente informado y es concebible desde un punto de vista solipsista, lo razonable tiene lugar en la interacción y encarna la conciencia moderna de la incertidumbre del futuro, las falibilidades cognitivas humanas, así como la posibilidad de errores ${ }^{3}$. En ese sentido, la persona razonable generalmente se compara con el hombre racional. $\mathrm{Si}$ bien este último es el maximizador perfecto y mide todos sus cursos de acción desde un punto de vista económico, equilibrando los beneficios y los costos, el primero se ve con frecuencia como una persona que interactúa con otros e interesados en buscar términos justos de cooperación. Por lo tanto, las personas razonables son generalmente conscientes de los pros y los contras de todas las opciones. También son conscientes de que las creencias pueden estar equivocadas y los deseos no pueden satisfacerse a toda costa ${ }^{4}$.

Ahora bien, admitiendo la distinción entre la persona racional y la razonable, es preciso detenernos en cómo el discurso jurídico gestiona estas categorías, es decir cómo les da sentido. Bazán y Madrid ${ }^{5}$ subrayan que entre los distintos usos de "lo razonable" en la jurisprudencia del Tribunal Constitucional español, uno de ellos se refiere, precisamente, a "lo ordinario, lo normal, esperable"6, este es el significado de lo razonable

2 SIBLEY, W. M.: "The Rational versus the Reasonable”. En: The Philosophical Review. Vol. 62, No. 4, 1953. pp. 556.

3 ZORZETTO, Silvia: "Reasonableness". En: The Italian Law Journal. Vol..1, No.1, 2015. p.113.

4 RIPSTEIN, Arthur.: "Reasonable Persons in Private Law". En: BONGIOVANNI, Giorgio, SARTOR, Giovanni y VALENTINI, Chiara, Reasonableness and Law, Springer, 2009. pp. 253-281

5 BAZÁN, Luis y MADRID, Raúl: "Racionalidad y razonabilidad". En: Revista Chilena de Derecho, Vol. 18, No. 2, 1991. pp.181-182.

6 "Lo razonable" como "lo esperable": STC 30/87, 11 de marzo, FJ 2: "Lo garantizado en mérito del principio de igualdad a quienes demanden justicia ante los Tribunales no es la obtención de una resolución igual a las que se hayan adoptado o puedan adoptarse en el futuro por el mismo órgano judicial, sino, más estrictamente, la razonable confianza -enlazada con la seguridad jurídica que la Constitución consagra- de que la propia pretensión merecerá del juzgador la misma respuesta obtenida por otros casos iguales". Lo razonable como "normal u ordinario": STC 69/89, 20 de abril, FJ $1^{\circ}$ "No vulnera la exigencia de lex certa que incorpora el artículo 25 de la Constitución la regulación de tales supuestos ilícitos mediante conceptos jurídicos indeterminados, siempre que 
cuando hablamos del "reasonable man" o "buen padre de familia" como modelo generalizado de diligencia. Lo que propugna este modelo (que al apelar a la responsabilidad del ciudadano medio establece un patrón generalizable de comportamiento y, por lo tanto, de exigible cumplimiento, salvo causa justificada) es la exclusión, en cuanto a su exigibilidad, de la conducta extraordinaria. Esto supone la definición de un estereotipo humano: la persona razonable conocida ${ }^{7}$.

La pretensión de un accionar razonable por parte del sujeto de derecho se ve atravesada por la indeterminación de esa adjetivación, debido a que se trata de una noción de contenido variable, tanto en un sentido histórico o social como en un sentido lógico Por eso, Atienza sostiene que la noción de razonabilidad es un componente común de lo que suele llamarse "conceptos jurídicos indeterminados", que vendrían a ser el resultado de la aplicación, a campos distintos, de un mismo concepto básico, el de razonabilidad ${ }^{8}$.

En ese sentido, Recaséns Siches planteó la insuficiencia o inadecuación de la lógica tradicional, de la lógica físico-matemática o de lo "racional" para trata con problemas prácticos como el de la interpretación del derecho. En su opinión, la lógica formal no agota ni remotamente la totalidad del logos, de la razón, sino que es tan sólo una provincia o un sector. Aparte de la lógica de lo racional, aparte de la lógica formal de la inferencia, hay otras regiones que pertenecen igualmente al logos, pero que son de índole muy diversa de aquella lógica de lo racional en sentido estricto. Entre esas zonas o regiones, figura el ámbito del logos de los problemas humanos de conducta práctica, al que llama logos de lo razonable ${ }^{9}$

Por su parte, en la teoría de la argumentación o nueva retórica de Perelman, la noción de lo razonable juega igualmente un papel central. Lo irrazonable represente para Perelman el límite negativo de cualquier argumentación jurídica y, en general, de cualquier argumentación práctica. Se trata de una noción variable histórica y socialmente, y que además remite a una pluralidad de soluciones posibles, dicho de otra manera, una decisión jurídica no puede (no debe) nunca ser irrazonable, pero dos o más decisiones

su concreción sea razonablemente factible en virtud de criterios lógicos, técnicos o de experiencia y permitan prever, por consiguiente, con suficiente seguridad, la naturaleza y las características esenciales de las conductas constitutivas de la infracción tipificada".

7 ZORZETTO, cit., p. 114.

8 ATIENZA, Manuel: "Para una razonable definición de razonable". En: DOXACuadernos de Filosofía del Derecho, No. 4, 1987. p.190.

9 RECASÉNS SICHES, Luis: Experiencia jurídica, naturaleza de la cosa y lógica razonada. Dianoia, México, 1971. p. 519. 
jurídicas pueden ser, todas ellas, razonables. Ahora bien, el que se trate de una noción variable no implica que sea también una noción confusa. No lo sería porque, para Perelman, lo razonable tiene un límite que viene marcado por el auditorio; esta última noción, es central en la concepción de la argumentación jurídica. "Es irrazonable lo que es inadmisible en una comunidad en un momento determinado" ${ }^{10}$. Como ha indicado Aarnio, el concepto de auditorio que marca el límite de lo aceptable o lo razonable, adolece, en la obra de Perelman, de una cierta ambigüedad pues, por un lado,s e ocnfigura como un acuerdo o un consenso ideal y, por otro lado, parece estar ligado a hechos contingentes de carácter social y cultural. Otra dificultad del concepto, indica Atienza, estriba en su escasa potencialidad crítica, desde el momento en que Perelman presupone que, ante un mismo caso, pueden tomarse diversas decisiones que (si respetan ciertos límites, que parecen configurarse de manera clara) habría que considerar como aceptables y, por tanto, como igualmente justificables ${ }^{11}$.

De cualquier modo, parece claro que lo que es razonable depende tanto de hechos como de valores que no están predeterminados. Esto significa que los criterios abstractos de razonabilidad no existen en clave absoluta y lo razonable es poroso y depende del contexto ${ }^{12}$. Por eso, sostenemos que el contenido que se le atribuya, sobre todo al momento de la decisión judicial, dependerá en gran medida del orden de significación instituido.

\section{Las expectativas del ordenamiento jurídico: ¿Qué espera el derecho de sus destinatarios?}

Asumiendo el carácter "poroso" e históricamente connotado de la razonabilidad, la identificación de algunas referencias del ordenamiento jurídico argentino puede dar cuenta de la función que desempeña $\mathrm{y}$ permitirnos trazar algunas conclusiones parciales.

El Código Civil y Comercial de la Nación Argentina, contiene expectativas manifiestas de conductas razonables por parte de los sujetos. Por ejemplo, al regular las obligaciones de las partes en ciertos contratos

10 PERLEMAN, Chaim: Le raisonnable el le déraisonnable en droit. L.G.L.J, París, 1984. p. 15.

11 ATIENZA, cit., p. 191.

12 ZORZETTO, cit., p. 110. 
(compraventa ${ }^{13}$, locación de obra ${ }^{14}$, transporte ${ }^{15}$ ) exige un comportamiento de conformidad con lo que "razonablemente cabe esperar" de acuerdo a la posición de la que se trate.

La figura del buen hombre de negocios, como objetivación del estereotipo de razonabilidad, también tiene su lugar en el derecho argentino. La Ley de Sociedades Comerciales, establece que "los administradores y los representantes de la sociedad deben obrar con lealtad y con la diligencia de un buen hombre de negocios"16. Asimismo, en la Ley de Contrato de Trabajo se prevé que las partes deben ajustar sus conductas "a lo que es propio de un buen empleador y de un buen trabajador"17. Incluso, las normas procesales contienen un estándar de conducta razonable a la hora de evaluar el accionar temerario o malicioso de las partes en el litigio ${ }^{18}$.

El discurso de los jueces, asimismo, ha recurrido al criterio de la razonabilidad para definir los límites de las expectativas jurídicas en relación con el comportamiento de los sujetos. Se ha referido, por ejemplo, al nivel de información que una persona razonable debería tener al momento de tomar una decisión ${ }^{19}$, al modo en que se aprecia un hecho delictivo desde la óptica de cualquier persona razonable ${ }^{20}$, incluso ha acudido a la noción de "buen padre de familia" para definir cuál es sentido común vigente a la hora de articular ciertas contrataciones ${ }^{21}$. De hecho, el modelo del sujeto razonable resultó fundamental para atribuirle significación a reglas jurídicas como la que dispone el deber de seguridad en los espectáculos deportivos, en el significativo precedente "Mosca" Allí, la Corte Suprema de la Nación Argentina dispuso que "una persona razonable y cuidadosa

13 Código Civil y Comercial de la Nación Argentina, artículo 1141: "Realizar todos los actos que razonablemente cabe esperar del comprador".

14 Código Civil y Comercial de la Nación Argentina, artículo 1256: "Ejecutar el contrato conforme a las previsiones contractuales y a los conocimiento razonablemente requeridos al tiempo de su realización por el arte, la ciencia y la técnica correspondientes a la actividad desarrollada".

15 Código Civil y Comercial de la Nación Argentina, artículo 1317: "El transportista de emplear una "razonable diligencia" en la contratación del transportista siguiente".

16 Ley 19.550, artículo 59.

17 Ley 20.744, artículo 68.

18 Código Procesal Civil y Comercial de la Nación Argentina, artículo 45.

19 Corte Suprema de Justicia de la Nación Argentina, "Noejovich, Raúl Adrián c/ Rodríguez, Néstor s/ ejecutivo", 27/05/2009.

20 Corte Suprema de Justicia de la Nación Argentina, "Scheffer, Ana Teresa c/ Nación Argentina y otro s/ daños y perjuicios", 24/08/2000, considerando 10.

21 Dictamen de la Procuración General de la Nación, "Denuncia s/presuntas irregularidades en el Banco de la Provincia de Rio Negro", 14/02/2008, considerando 3. 
que organiza un espectáculo debe ponderar los riesgos que existen en el acceso al mismo o sus inmediaciones, y adoptar las diligencias necesarias para evitarlos. El organizador debe proteger al espectador ubicado dentro del estadio, cuando accede al mismo para ver el espectáculo y, cuando está a unos metros de la entrada. Es irrazonable pensar que una persona accede a su riesgo antes de la puerta y, por el contrario, está asegurada por el organizador cuando traspasa ese umbral, siendo que la fuente de riesgo es la misma: la organización de un espectáculo sobre la base de la tolerancia excesiva y negligente de las hinchadas" ${ }^{22}$.

En efecto, el sujeto de derecho, configurado a partir de un tipo de racionalidad que históricamente incluyó y excluyó (mujeres, niños, niñas, personas con discapacidad, pueblos indígenas), es parte de un orden de significación instituido. De tal modo, la definición de ciertos modos de conducirse, capturados por el estándar de razonabilidad, también cristalizan tensiones, conflictos y acuerdos coyunturales. Las referencias normativas identificadas y la concretización de la idea de razonabilidad que han desplegado los tribunales, permite advertir que su "porosidad" habilita un diálogo propicio entre los textos jurídicos y los contextos, constituyéndose incluso en una oportunidad para interpretaciones innovadoras (piénsese, por ejemplo, en las formas de entender la idea de "buen padre de familia" a través de las transformaciones operadas por el paradigma de los derechos humanos). Sin embargo, también es susceptible de convertirse en un terreno fértil para la arbitrariedad y la afectación de la seguridad jurídica (cognoscibilidad, confiabilidad y calculabilidad ${ }^{23}$ ).

\section{EL JUEZ Y LA RAZONABILIDAD.}

\section{Introducción}

En los apartados anteriores, hemos abordado las diferencias centrales entre racionalidad y razonabilidad con referencia al sujeto de derecho, propiciando una reflexión en torno a cuáles son las pretensiones del sistema jurídico respecto de la conducta de sus destinatarios. En ese sentido, advertimos que las normas del ordenamiento apelan a categorías de carácter poroso (el hombre razonable, el buen hombre de negocios, el buen padre

22 Corte Suprema de Justicia de la Nación Argentina, Fallos: 330:563, "Mosca, Hugo Arnaldo c/ Buenos Aires, Provincia de (Policía Bonaerense) y otros s/ daños y perjuicios", 06/03/2007, considerando 7.

23 ÁVILA, Humberto: Teoría de la Seguridad Jurídica. Marcial Pons- Cátedra de Cultura Jurídica, Madrid, 2012. p. 580. 
de familia, etc.) cuyo contenido acaba por determinarse, en general, en el plano jurisdiccional.

En esta oportunidad, procuraremos establecer cuáles son los marcos de actuación de las autoridades judiciales en el contexto del Estado de derecho para gestionar el conflicto y la incertidumbre. En consecuencia, además de proporcionar los elementos teóricos fundamentales adoptaremos como hilo conductor algunos ejemplos de la jurisprudencia argentina en circunstancias de emergencia, con el propósito de identificar el impacto que allí cobra la "razonabilidad" del decisor.

\section{Un juez razonable para el Estado de Derecho}

Lo razonable no solo está determinado por la cultura, sino que también está profundamente influenciado por sus antecedentes filosóficos y políticos ${ }^{24} \mathrm{y}$, podríamos decir, la razonabilidad opera como un límite al arbitrio del poder. Massimo Cuono, identifica, ex negativo, cinco significados de razonabilidad de los actos del poder: a) irrazonable como insensato, es decir, aquel soberno que no usa la razón para empler los medios idóneos para alcanzar los fines deseados en su propia actuación; b) irrazonable como inicuo, refiriéndose al problema de la equidad, entendida como la justicia en el caso concreto, en términos aristotélicos; c) irrazonable como discriminatorio, asumiendo una vinculación de la razonabilidad con el principio de igualdad; d) irrazonable como inmoral, identificando como irrazonables aquellos actos contrarios a la dictamina rectae rationis, permitiendo incluso, tal como sostiene Radbruch, la exclusión de las leyes a las que les falte total sentido de la verdad y del Derecho; e) irrazonable como inflexible, incluyendo en esta categoría a los actos de los gobernantes incapaces de tomar en consideración las razones de otros, es decir, ser razonable supone darse cuenta de las circunstancias y de las limitaciones que éstas implican con la renuncia a una actitud, teórica o práctica, de absolutismo ${ }^{25}$. Los últimos dos sentidos son los de recurrencia más frecuente por las perspectivas denominadas neoconstitucionalistas.

Lo que subyace, en definitiva, es que más allá los posibles contenidos, la necesidad de un juez razonable se funda en el presupuesto

24 ZORZETTO, cit., p. 113.

25 CUONO, Massimo: "Entre arbitrariedad y razonabilidad: hacia una teoría crítica del neoconstitucionalismo". En: Eunomía, Revista en Cultura de la Legalidad, No. 3, 20122013. pp. 46-49. 
de que el ordenamiento jurídico no proporciona todas las respuestas o, por lo menos, que el acontecimiento judicial tiene carácter realizativo, zanja la distancia entre el registro general dado por la regla y la singularidad del $\mathrm{caso}^{26}$. El modo de disciplinar esa actividad, implica, inicialmente, subrayar que no todo uso del poder legal es aceptable y se espera que el decisor adhiera lo más posible a la certeza jurídica. Según Aarnio, la expectativa de certeza jurídica sensu stricto significa que todo ciudadano tiene el derecho de esperar protección jurídica. Sin embargo, la expectativa de certeza jurídica también puede ser entendida en un sentido más amplio (sensu largo), cubriendo dos elementos: a) que se evite la arbitrariedad y b) que la decisión sea "correcta". Ninguno de estos dos elementos satisface por sí solo la expectativa ${ }^{27}$. En ese sentido, la autoridad se ve confrontada permanentemente con la incertidumbre de los contenidos del sistema jurídico y cuando se dispone a especificarlos, tiene que lograr un equilibrio entre dos objetivos que apuntan en direcciones opuestas: respetar la estabilidad y procurar la flexibilidad requerida por las circunstancias. El primero de esos objetivos sirve a la continuidad, a la igualdad formal de los ciudadanos ante la ley, y permite que las relaciones sociales puedan ser anticipadas. El segundo, intenta registrar los cambios de la sociedad, puesto que si el derecho no se ajusta a su ritmo, actúa como un freno del desarrollo. En este sentido, se ha presentado la distinción entre derecho y razonabilidad, Peczenik la formulado como una tensión entre previsibilidad y justicia ${ }^{28}$.

En la propuesta de Dworkin, la solución a la autoridad razonable radica en la figura del juez "Hércules" 29 , capaz de arribar a la respuesta correcta. Este personaje ficticio "lo sabe todo, dispone de tiempo para tomar la decisión, su información sobre el caso y sobre los argumentos relevantes es ilimitada" ${ }^{30}$, en palabras de Habermas, es demasiado heroico, sus construcciones narrativas son monológicas, no conversa con nadie, si no es a través de libros, nada le conmociona ${ }^{31}$. Es decir, se trata de una figura

26 DERRIDA, Jacques: Fuerza de ley: el fundamento místico de la autoridad. Tecnos, Madrid, 1997. p. 52.

27 AARNIO, Auris: Lo racional como razonable. Centro de Estudios Constitucionales, Madrid, 2001. p. 26.

28 Ibídem, p. 33.

29 DWORKIN, Ronald: Los derechos en serio. Ariel, Barcelona, 1984. p. 177.

30 AARNIO, Auris: "La tesis de la única respuesta correcta y el principio regulativo del razonamiento jurídico". En: DOXA- Cuadernos de Filosofía del Derecho, No. 4, 1990. p. 31.

31 HABERMAS, Jürgen: Facticidad y Validez: Sobre el Derecho y el Estado democrático de Derecho en términos de Teoría del Discurso. Trotta, Madrid, 2005. p. 295. 
ideal, que desconoce a la otredad, pues desconoce a todo interlocutor que pueda interferir en su insular espacio de decisión, es una suerte de hombre "después de todo", inmune a la pluralidad. Prieto Sanchís, advierte con buen juicio, las razones por las que Dworkin desemboca en este modelo de juez y señala que quienes realmente creyeron en la autosuficiencia del derecho nunca pensaron en un juez Hércules, sino en todo lo contrario, en jueces populares: una vez elaborado el Código racional, completo y coherente, el procedimiento judicial habría de reducirse a un simple juicio de hecho verificable por cualquier persona. En cambio, si Dworkin precisa idear un juez como Hércules, tal vez sea porque no le ofrece un derecho claramente delimitado, sino un complejo sistema de normatividad social en el que se entrecruzan reglas jurídicas y morales ${ }^{32}$.

Nos enfrentamos, en suma, a un espacio de discrecionalidad que, para Hart, se trata de un lugar intermedio entre las elecciones dictadas por el puro capricho personal o momentáneo y aquéllas realizadas en aplicación de métodos claros para alcanzar objetivos definidos o para adecuarse a reglas cuya aplicación al caso concreto resulta evidente ${ }^{33}$. Es decir, entender a la discrecionalidad como un ámbito donde los argumentos pueden ser razonables sin ser definitivos.

\section{La razonabilidad judicial en contextos de emergencia.}

Con el objeto de ilustrar la trascendencia que ha adquirido el apego a la razonabilidad de la decisión judicial, recurriremos a ciertos precedentes de la Corte Suprema de la Nación Argentina en circunstancias de emergencia. Inicialmente, debe decirse que durante los años 2001 y 2002 el Estado argentino atravesó una frenética crisis económica con impactos jurídicos manifiestos ${ }^{34}$ que motivaron diversos pronunciamientos donde resultó

32 PRIETO SANCHÍS, Luis: “Teoría del Derecho y Filosofía Política en Ronald Dworkin”. En: Revista Española de Derecho Constitucional, Año 5. Núm. 14, mayo-agosto 1983. pp. 367-368.

33 HART, Herbert L.A: "Discrecionalidad". En: DOXA- Cuadernos de Filosofía del Derecho, No. 37, 2014. p. 92.

34 En el marco de la situación de emergencia el Estado Nacional dictó medidas por las que se restringió la disponibilidad de los depósitos bancarios y se estableció la conversión a pesos de los efectuados en moneda extranjera (decretos 1570/01; ley 25.561 y decreto 214/02). Los depósitos constituidos en moneda extranjera, fueron convertidos a pesos a la relación de $\$ 1,40$ por cada dólar estadounidense y ajustados por el coeficiente de estabilización de referencia (CER) sin perjuicio del reconocimiento de intereses (arts. 2 y 4 del decreto 214/ 02). En relación con los contratos vigentes, la ley 25.561 dispuso 
imprescindible resolver la tensión resolver la tensión referida entre estabilidad y flexibilidad.

En primer término, si bien la Corte Suprema admitió, lo que en términos de Hart podría denominarse la "Discrecionalidad Reconocida" de la Administración Pública, determinó que es incontrovertible el deber del Poder Judicial de controlar la razonabilidad y constitucionalidad de tales medidas, máxime cuando, como en el caso, éstas se traducen en normas sujetas a bruscos y veloces cambios ${ }^{35}$.

Concretamente, al momento de juzgar las decisiones adoptadas en un profundo escenario de crisis, el tribunal determinó que "en tal contexto, la pesificación se presenta como razonable mientras el importe que se devuelva tenga el mismo o mayor poder adquisitivo que tenía el depósito originario, ya que ello no causa perjuicio alguno al acreedor. Fue, por lo demás, una medida razonable frente a la situación de fuerza mayor trasuntada en la emergencia" ${ }^{36}$. Es decir, frente a la aplicación ciega de las disposiciones del Código Civil ${ }^{37}$ y la protección de la propiedad privada, el juzgador recurre a la razonabilidad, propiciando una adecuación a la excepcionalidad de la controversia.

En otro asunto, vinculado a la misma problemática, concluyó que a la luz de las referidas orientaciones normativas, se presentan, básicamente, dos caminos alternos para dar solución a problemas suscitados, a) aplicar los parámetros indicados en las prescripciones legales referidas en los considerandos anteriores; y 2) ordenar la distribución equitativa entre los contendientes de las consecuencias de la variación cambiaria.La segunda solución es la respuesta que se impone a efectos de alcanzar una recomposición justa y razonable de las prestaciones, haciendo efectiva

en su art. 11 que las prestaciones dinerarias exigibles desde su fecha de promulgación, originadas en los contratos celebrados entre particulares en moneda extranjera, fuesen canceladas en pesos a la relación de cambio de un peso igual a un dólar estadounidense, en concepto de pago a cuenta de la suma que, en definitiva, resultara de la reestructuración de las obligaciones que las partes debían negociar durante un plazo no mayor a los 180 días, procurando compartir de modo equitativo los efectos de la modificación de la relación de cambio.

35 Corte Suprema de Justicia de la Nación Argentina, "Provincia de San Luis c/ Estado Nacional", 05/03/2003.

36 Corte Suprema de Justicia de la Nación Argentina, "Bustos, Alberto Roque y otros c/ E.N. y otros s/ amparo", 26/10/2004.

37 Artículos 617 y 619 del entonces vigente Código Civil exigían el pago de las obligaciones en la moneda convenida por las partes. 
la regla de equidad que constituye el eje sobre el que la legislación de emergencia ha procurado hacer girar todo sistema de reajuste ${ }^{38}$.

Asimismo, al pronunciarse acerca de los efectos de las medidas de emergencia en materia de contratos de mutuo hipotecario, destacó que "si bien es cierto que según lo dispuesto por el Código Civil, el deudor debe resarcir los daños e intereses que su morosidad causare, para juzgar si corresponde hacerlo responsable por los efectos de la emergencia y de la devaluación, no sólo debe ponderarse la magnitud de la depreciación de nuestra moneda que desquició las bases del contrato, sino también que aquellos hechos desbordaron el grado de previsibilidad que podía exigirse a un obrar razonable ${ }^{39}$.

\section{CONCLUSIONES Y PERSPECTIVAS.}

A lo largo de este ensayo se ha procurado problematizar las narrativas a partir de las cuales se construye el sentido de la razonabilidad, colocando, en primer lugar, el acento en los modelos de sujeto configurados por el ordenamiento jurídico que definen qué es lo que se espera de sus destinatarios. Modelos que pueden convertirse en vehículos de estereotipos y prejuicios vigentes en el orden de significaciones instituido, pero que, la noción de "razonabilidad", por su propia flexibilidad, permite a los jueces ajustarla a las necesidades de los tiempos históricos.

En definitiva, se reedita mediante la discusión por el sentido de lo razonable un debate persistente referido a la determinación o indeterminación del derecho y al papel de los tribunales en ese escenario. Por esa razón, se han recogido antecedentes vinculados a contextos de emergencia, que alteraron manifiestamente las condiciones del sistema económico y financiero, y que evidenciaron - una vez más- las limitaciones de la maquinaria legislativa para prever determinados acontecimientos. Allí, la labor de la judicatura se tradujo en atribuirle significado al estándar

38 Corte Suprema de Justicia de la Nación Argentina, "Longobardi, Irene Gwendoline y otros c/ Instituto de Educación Integral San Patricio S.R.L", 18/12/2007.

39 Corte Suprema de Justicia de la Nación Argentina, "Rinaldi, Francisco Augusto y otro c/ Guzmán Toledo, Ronal Constante y otra s/ ejecución hipotecaria", 15/03/2007. Allí, la Corte agregó: "Quienes se obligaron durante la vigencia de la ley de convertibilidad no lo hicieron respecto de una moneda extranjera que fluctuaba libremente en el mercado cambiario y podía tener altibajos; su voluntad tuvo el marco de referencia normativo dado por el Estado que les aseguraba la paridad fijada por la ley 23.928, reafirmada por disposiciones de variada índole durante el lapso anterior a la sanción de la ley 25.561". 
de "razonabilidad", recurriendo, por ejemplo, a las ideas de "flexibilidad" y "equidad", intentando resolver los problemas enquistados en una aplicación fría de las condiciones contractuales y legales, diseñadas para otro tipo de circunstancias.

En efecto, el recorrido propuesto da cuenta de que la omnisciencia y el carácter sobrehumano del "Hércules" propuesto por Dworkin, recibe, a través de estas formas de entender la razonabilidad, algunas heridas en su narcisismo. Quizás, un Hércules terrenal, sensible a los vaivenes de las culturas y de los tiempos históricos, estaría más cerca de expresar el tipo de juzgador necesario para un Estado de derecho. Pero, ya no sería Hércules.

\section{BIBLIOGRAFÍA.}

AARNIO, Auris: "La tesis de la única respuesta correcta y el principio regulativo del razonamiento jurídico". En: DOXA-Cuadernos de Filosofía del Derecho, No. 4, 1990.

AARNIO, Auris: Lo racional como razonable. Centro de Estudios Constitucionales, Madrid, 2001.

ATIENZA, Manuel: "Para una razonable definición de razonable". En: DOXA-Cuadernos de Filosofía del Derecho, No. 4, 1987.

ÁVILA, Humberto: Teoría de la Seguridad Jurídica. Marcial Pons- Cátedra de Cultura Jurídica, Madrid, 2012.

BAZÁN, Luis y MADRID, Raúl: "Racionalidad y razonabilidad". En: Revista Chilena de Derecho, Vol. 18, No. 2, 1991.

CUONO, Massimo: "Entre arbitrariedad y razonabilidad: hacia una teoría crítica del neoconstitucionalismo". En: Eunomía, Revista en Cultura de la Legalidad, No. 3, 2012-2013.

DERRIDA, Jacques: Fuerza de ley: el fundamento místico de la autoridad. Tecnos, Madrid, 1997.

DWORKIN, Ronald: Los derechos en serio. Ariel, Barcelona, 1984.

HABERMAS, Jürgen: Facticidad y Validez: Sobre el Derecho y el Estado democrático de Derecho en términos de Teoría del Discurso. Trotta, Madrid, 2005. 
HART, Herbert L.A: "Discrecionalidad". En: DOXA- Cuadernos de Filosofía del Derecho, No. 37, 2014.

HEIDEGGER, Martin: "La época de la imagen del mundo". En: Caminos de Bosque. Alianza, Madrid, 1996.

PERLEMAN, Chaim: Le raisonnable el le déraisonnable en droit. L.G.L.J, París, 1984.

PRIETO SANCHÍS, Luis: "Teoría del Derecho y Filosofía Política en Ronald Dworkin". En: Revista Española de Derecho Constitucional, Año 5. Núm. 14, Mayo-agosto 1983.

RECASÉNS SICHES, Luis: Experiencia jurídica, naturaleza de la cosa y lógica razonada. Dianoia, México, 1971.

RIPSTEIN, Arthur.: "Reasonable Persons in Private Law". En: BONGIOVANNI, Giorgio, SARTOR, Giovanni y VALENTINI, Chiara: Reasonableness and Law, Springer, 2009.

SIBLEY, W. M.: "The Rational versus the Reasonable". En: The Philosophical Review. Vol. 62, No. 4, 1953.

ZORZETTO, Silvia: "Reasonableness". En: The Italian Law Journal. Vol. 1, No.1, 2015. 